\title{
Genetics of phosphate solubilization and its potential applications for improving plant growth-promoting bacteria
}

\author{
H. Rodríguez ${ }^{1,2, *}$, R. Fraga ${ }^{1}$, T. Gonzalez ${ }^{1} \&$ Y. Bashan ${ }^{2}$ \\ ${ }^{1}$ Dept. of Microbiology, Cuban Research Institute on Sugar Cane By-Products (ICIDCA), 4026, CP 11000 , \\ Havana, Cuba. ${ }^{2}$ Environmental Microbiology Group, Center for Biological Research of the Northwest (CIB), \\ La Paz B.C.S., Mexico. ${ }^{1}$ Corresponding author*
}

Received: 31 May 2006

Key words: genetically modified microorganisms, organic acids, phosphatases, phosphorus solubilization, phytases, plant growth promoting bacteria

\begin{abstract}
Plant growth-promoting bacteria (PGPB) are soil and rhizosphere bacteria that can benefit plant growth by different mechanisms. The ability of some microorganisms to convert insoluble phosphorus (P) to an accessible form, like orthophosphate, is an important trait in a PGPB for increasing plant yields. In this mini-review, the isolation and characterization of genes involved in mineralization of organic P sources (by the action of enzymes acid phosphatases and phytases), as well as mineral phosphate solubilization, is reviewed. Preliminary results achieved in the engineering of bacterial strains for improving capacity for phosphate solubilization are presented, and application of this knowledge to improving agricultural inoculants is discussed.
\end{abstract}

\section{Introduction}

Plant growth-promoting bacteria (PGPB) are soil and rhizosphere bacteria that can benefit plant growth by different mechanisms (Glick, 1995). Given the negative environmental impact of chemical fertilizers and their increasing costs, the use of PGPB as natural fertilizers is advantageous for the development of sustainable agriculture.

There are two components of $\mathrm{P}$ in soil, organic and inorganic phosphates. A large proportion is present in insoluble forms, and therefore, not available for plant nutrition. Inorganic $\mathrm{P}$ occurs in soil, mostly in insoluble mineral complexes, some of them appearing after the application of chemical fertilizers. These precipitated forms cannot be absorbed by plants. Organic matter, on the other hand, is an important

\footnotetext{
* Fax No: + 53-7-338236.

E-mail: hildadiaxi03@yahoo.com
}

reservoir of immobilized $\mathrm{P}$ that accounts for $20-80 \%$ of soil P (Richardson, 1994). To convert insoluble phosphates (both organic and inorganic) to a form accessible to the plants, like orthophosphate, is an important trait for a PGPB for increasing plant yields.

Molecular biology techniques are an advantageous approach for obtaining and characterizing improved PGPB strains (Igual et al., 2001; Rodríguez and Fraga, 1999). Release of genetically modified organisms is controversial. While some countries encourage it, others prohibit the use of the technology and require labeling of products containing genetically modified food ingredients. However, studies carried out so far have shown that following appropriate regulations, genetically modified microorganisms can be applied safely in agriculture (Armarger, 2002; Morrissey et al., 2002). Chromosomal insertion of the genes is one of the tools to avoid horizontal transfer of the introduced genes within the rhizosphere. 
Some barriers should be overcome first to achieve successful gene insertions using this approach, such as the dissimilarity of metabolic machinery and different regulating mechanism between the donor and recipient strains. Despite the difficulties, significant progress has been made in obtaining genetically engineering microorganisms for agricultural use (Armarger, 2002).

There are several advantages of developing genetically-modified PGPB over transgenic plants for improving plant performance: (1) With current technologies, it is far easier to modify a bacterium than complex higher organisms, (2) Several plant growth-promoting traits can be combined in a single organism, and (3) Instead of engineering crop by crop, a single, engineered inoculant can be used for several crops, especially when using a nonspecific genus like Azospirillum.

Introduction or over-expression of genes involved in soil phosphate solubilization (both organic and inorganic) in natural rhizosphere bacteria is a very attractive approach for improving the capacity of microorganisms to work as inoculants. Insertion of phosphate-solubilizing genes into microorganisms that do not have this capability may avoid the current need of mixing two populations of bacteria, when used as inoculants (nitrogen fixers and phosphate-solubilizers) (Bashan et al., 2000). We report on recent advances in the manipulation of genes related to microbial phosphate-solubilization and its relationship to rhizobacteria, as improved inoculants.

\section{Organic phosphate solubilization}

Phosphorus can be released from organic compounds in soil by three groups of enzymes: (1) Nonspecific phosphatases, which perform dephosphorylation of phospho-ester or phosphoanhydride bonds in organic matter, (2) Phytases, which specifically cause $\mathrm{P}$ release from phytic acid, and (3) Phosphonatases and C-P Lyases, enzymes that perform $\mathrm{C}-\mathrm{P}$ cleavage in organophosphonates. The main activity apparently corresponds to the work of acid phosphatases and phytases because of the predominant presence of their substrates in soil.

Availability of organic phosphate compounds for plant nutrition could be a limitation in some soils resulting from precipitation with soil particle ions. Therefore, the capability of enzymes to perform the desired function in the rhizosphere is a crucial aspect for their effectiveness in plant nutrition. Nevertheless, the efficiency of plant and microbial phosphatases on organic $\mathrm{P}$ depletion in the rhizosphere and $\mathrm{P}$ uptake by plants has been well documented (Tarafdar and Jungk, 1987; Tarafdar and Claassen, 1988).

\section{Nonspecific acid phosphatases}

Bacterial nonspecific acid phosphatases (phosphohydrolases) (NSAPs) are formed by three molecular families, which have been designated as molecular class A, B, and C (Thaller et al., 1995a). From their cellular location, these enzymes seem to function as organic phospho-ester scavengers, providing the cell with essential nutrients (releasing inorganic phosphates from nucleotides and sugar phosphates, for example, while the organic by-products are incorporated into the cell) (Beacham, 1980; Wanner, 1996).

Interest in these enzymes has increased during the last decade because of their potential biotechnological applications. Macaskie et al. (1997) reported on the successful use of Class A NSAPs as tools for environmental bioremediation of uranium-bearing wastewater, and Baskanova and Macaskie (1997) and Bonthrone et al. (1996) on heavy metal biomineralization (particularly $\mathrm{Ni}^{2+}$ ). A new biotechnological application for NSAPs would be to transfer and express these genes in PGPB to obtain improved phosphatesolubilizing strains using recombinant DNA technology.

Several acid phosphatase genes from Gramnegative bacteria have been isolated and characterized (Rossolini et al., 1998). These cloned genes represent an important source of material for the genetic transfer of this trait to PGPB strains. Some of them code for acid phosphatase enzymes that are capable of performing well in soil. For example, the acpA gene isolated from Francisella tularensis expresses an acid phosphatase with optimum action at $\mathrm{pH} 6$, with a wide range of substrate specificity (Reilly et al., 1996). Also, genes encoding nonspecific acid phosphatases class A (PhoC) and class B (NapA) isolated from Morganella morganii are very promising, since the biophysical and functional properties of the encoded enzymes were extensively studied 
(Thaller et al., 1994; Thaller et al., 1995b). Besides, they are P-irrepressible enzymes showing broad substrate action and high activity around pH 6 and $30^{\circ} \mathrm{C}$.

Among rhizobacteria, a gene from Burkholderia cepacia that facilitates phosphatase activity was isolated (Rodríguez et al., 2000a). This gene codes for an outer membrane protein that enhances synthesis in the absence of soluble phosphates in the medium, and could be involved in $\mathrm{P}$ transport to the cell. Besides, cloning of two nonspecific periplasmic acid phosphatase genes (napD and napE) from Rhizobium (Sinorhizobium) meliloti was accomplished (Deng, et al., 1998, 2001).

Heterologous expression of these genes in agriculturally important bacterial strains would be the next step in programs of improving organic phosphate mineralization in PGPB. The nap $A$ phosphatase gene from the soil bacterium Morganella morganii was transferred to Burkholderia cepacia IS-16, a strain used as a biofertilizer, using the broad-host range vector pRK293 (Fraga et al, 2001). An increase in extracellular phosphatase activity of the recombinant strain was achieved.

Insertion of the transferred genes into the bacterial chromosome is advantageous for stability and ecological safety. In our lab, a plasmid for the stable chromosomal insertion of the phoC phosphatase gene from Morganella morganii was constructed, based on the delivery system developed by de Lorenzo et al. (1990). This plasmid was transferred to Azospirillum spp. Preliminary results indicate that strains with increased phosphatase activity were obtained.

\section{Phytases}

Most phytases (myo-inositol hexakisphosphate phosphohydrolases) belong to high molecular weight acid phosphatases. In its basic form, phytate is the primary source of inositol and the major stored form of phosphate in plant seeds and pollen. Nevertheless, monogastric animals are incapable of using the $\mathrm{P}$ bound in phytate because their gastrointestinal tracts have low levels of phytase activity. Thus, nearly all the dietary phytate phosphorus ingested by these species is excreted, resulting in phosphorus pollution in areas of intensive animal production, and why phytases have emerged as very attractive enzymes for industrial and environmental applications. Genetic studies of phytases began in 1984, and the first commercial phytase, produced by genetically modified microorganisms, appeared on the market in the mid 1990s (Yanming et al., 1999).

Most genetic engineering studies have focused on the search for phytases that are optimal for improving animal nutrition. Another attractive application of these enzymes that is not currently exploited is solubilization of soil organic phosphorus through phytate degradation. Phytate is the major component of organics forms of $\mathrm{P}$ in soil (Richardson, 1994). The ability of plants to obtain phosphorus directly from phytate is very limited. However, the growth and phosphorus nutrition of Arabidopsis plants supplied with phytate was improved significantly when they were genetically transformed with the phytase gene (phyA) from Aspergillus niger (Richardson et al., 2001a). This resulted in improved $\mathrm{P}$ nutrition, such that the growth and $\mathrm{P}$ content of the plant was equivalent to control plants supplied with inorganic phosphate.

The enhanced utilization of inositol phosphate by plants by the presence of soil microorganisms has also been reported (Richardson et al., 2001b). Therefore, developing agricultural inoculants with high phytase production would be of great interest for improving plant nutrition and reducing $\mathrm{P}$ pollution in soil. Although phytase genes have been cloned from fungi, plants, and bacteria (Lei and Stahl, 2001), we will discuss only bacteria because they are the most feasible for the genetic improvement of rhizobacteria.

Thermally stable phytase genes (phy) from Bacillus sp. DS11 (Kim et al., 1998a) and from B. subtilis VTT E-68013 (Kerovuo et al., 1998) has been cloned. Acid phosphatase/phytase genes from E. coli (appA and appA2 genes) have also been isolated and characterized (Golovan et al., 2000; Rodríguez et al., 1999). The bi-functionality of these enzymes makes them attractive for solubilization of organic $\mathrm{P}$ in soil. Also, neutral phytases have great potential for genetic improvement of PGPB. Neutral phytase genes have been recently cloned from $B$. subtilis and B. licheniformis (Tye et al., 2002), A phyA gene has been cloned from the FZB45 strain of $B$. amyloliquefaciens. This strain was isolated from a 
group of several Bacillus having plant-growthpromoting activity (Idriss et al., 2002). It showed the highest extracellular phytase activity, and diluted culture filtrates of these strains stimulated growth of maize seedlings under limited phosphate in the presence of phytate. Culture filtrates obtained from a phytase-negative mutant strain, whose phyA gene was disrupted, did not stimulate plant growth. In addition, growth of maize seedlings was enhanced in the presence of purified phytase and the absence of culture filtrate.

These experiments provide strong evidence that phytase activity can be important for stimulating growth under limited $\mathrm{P}$ in soil, and supports the potential of using phytase genes to improve or transfer the P-solubilizing trait to PGPB strains used as agricultural inoculants.

\section{Inorganic phosphate solubilization}

\section{Isolation of mineral phosphate-solubilizing (mps) genes}

In most bacteria, mineral phosphate-dissolving capacity has been shown to be related to the production of organic acid (Rodríguez and Fraga, 1999). Goldstein (1996) proposed direct glucose oxidation to gluconic acid (GA) as a major mechanism for mineral phosphate solubilization
(MPS) in Gram-negative bacteria. GA biosynthesis is carried out by the glucose dehydrogenase $(\mathrm{GDH})$ enzyme and the co-factor, pyrroloquinoline quinone (PQQ). Some genes involved in MPS in different species have been isolated (Table 1).

Goldstein and Liu (1987) were the first to clone a gene involved in MPS from the Gramnegative bacteria Erwinia herbicola. Expression of this gene allowed production of GA in E. coli HB101 and conferred the ability to solubilize hydroxyapatite. E. coli can synthesize GDH, but not PQQ, thus it does not produce GA. The cloned $1.8 \mathrm{~kb}$ locus encodes a protein similar to the gene III product of a $p q q$ synthesis gene complex from Acinetobacter calcoaceticus, and to pqqE of Klebsiella neumonie (Liu et al., 1992). These authors suggested that the E. herbicola DNA fragment functions as a PQQ synthase gene, and that probably, some E. coli strains contain some cryptic PQQ synthase genes that could be complemented by this single open reading frame (ORF) isolated by them.

Coincidentally, nucleotide sequence analysis of a $7.0 \mathrm{~kb}$ fragment from Rhanella aquatilis genomic DNA that induced hydroxyapatite solubilization in E. coli, showed two complete ORFs and a partial ORF. One of the cloned proteins showed similarity to $p q q E$ of $E$. herbicola, $K$. neumoniae, and A. calcoaceticus (Kim et al.,

Table 1. Cloning of genes involved in mineral phosphate solubilization (MPS)

\begin{tabular}{|c|c|c|c|}
\hline Microorganism & $\begin{array}{l}\text { Gene or } \\
\text { plasmid }\end{array}$ & Features & Reference \\
\hline Erwinia herbicola & $m p s$ & $\begin{array}{l}\text { Produces gluconic acid and solubilizes } \\
\text { mineral } \mathrm{P} \text { in } E \text {. coli } \mathrm{HB} 101 \\
\text { Probably involved in } \mathrm{PQQ}^{1} \text { synthesis }\end{array}$ & Goldstein and Liu (1987) \\
\hline Pseudomonas cepacia & $g a b \mathrm{Y}$ & $\begin{array}{l}\text { Produces gluconic acid and solubilizes } \\
\text { mineral P in E. coli JM109 } \\
\text { No homology with PQQ genes }\end{array}$ & Babu-Khan et al. (1995) \\
\hline $\begin{array}{l}\text { Enterobacter } \\
\text { agglomerans }\end{array}$ & pKKY & $\begin{array}{l}\text { Solubilizes } \mathrm{P} \text { in } E \text {. coli JM109 } \\
\text { Does not lower } \mathrm{pH}\end{array}$ & Kim et al. (1997) \\
\hline Rahnella aquatilis & $\mathrm{pK} 1 \mathrm{M} 10$ & $\begin{array}{l}\text { Solubilizes } \mathrm{P} \text { and produces gluconic } \\
\text { acid in } E \text {. coli } \mathrm{DH} 5 \propto \\
\text { Probably related to PQQ synthesis }\end{array}$ & Kim et al. (1998b) \\
\hline Serratia marcescens & pKG3791 & $\begin{array}{l}\text { Produces gluconic acid and solubilizes } \\
\text { mineral P }\end{array}$ & Krishnaraj and Goldstein (2001) \\
\hline $\begin{array}{l}\text { Synechococcus } \\
\text { PCC } 7942\end{array}$ & $p c c$ gene & Synthesizes phosphoenol pyruvate carboxylase & N. Kumar (pers. comm.) \\
\hline
\end{tabular}

PQQ: pyrroloquinoline quinone. 
1998b), while the partial ORF is similar to the $p q q C$ of $K$. neumoniae. These authors also report that these genes complement cryptic pqq E. coli genes, thus allowing GA production.

Another type of gene $(g a b Y)$ involved in GA production and MPS was cloned from Pseudomonas cepacia (Babu-Khan et al., 1995). The deduced amino acid sequence showed no homology with previously cloned direct oxidation pathway (GA synthesis) genes, but was similar to histidine permease membrane-bound components. In the presence of $g a b Y$, GA is produced only if the $E$. coli strain expresses a functional glucose dehydrogenase $(g c d)$ gene. The authors (Babu-Khan et al., 1995), speculated that this ORF could be related to the synthesis of PQQ by an alternative pathway, or the synthesis of a $g c d$ co-factor different from PQQ. The reported synergistic effect of exogenous PQQ and this gene supports this alternative, in our opinion. Also, a DNA fragment from Serratia marcenses induces GA synthesis in E. coli, but showed no homology to $p q q$ or $g c d$ genes (Krishnaraj and Goldstein, 2001). They suggested that this gene acted by regulating GA production under cell-signal effects.

Other isolated genes involved in the MPS phenotype seem not to be related with $p q q$ DNA or $g c d$ biosynthetic genes. A genomic DNA fragment from Enterobacter agglomerans showed MPS activity in E. coli JM109, although the pH of the medium was not altered (Kim et al., 1997). These results indicate that acid production is an important way, but not the only mechanism, of phosphate solubilization by bacteria (Illmer and Shinnera, 1995). More recently, a phosphoenol pyruvate carboxylase ( $p c c$ ) gene from Synechococcus PCC 7942 appears to be involved in MPS (Kumar Naresh, pers. comm.). All these findings demonstrate the complexity of MPS in different bacterial strains, but at the same time, offer a basis for better understanding of this process.

\section{Manipulation of mps genes for $P G P B$ improvement}

Expression in E. coli of the mps genes from Ranella aquatilis supported a much higher GA production and hydroxyapatite dissolution in comparison with the donor strain (Kim et al., 1998b). The authors suggested that different genetic regulation of the mps genes might occur in both species. MPS mutants of Pseudomonas spp. showed pleiotropic effects, with apparent involvement of regulatory $\mathrm{mps}$ loci in some of them (Krishnaraj et al., 1999). This suggests a complex regulation and various metabolic events related to this trait. Expression of a $m p s$ gene in a different host could be influenced by the genetic background of the recipient strain, the copy number of plasmids present, and metabolic interactions. Thus, genetic transfer of any isolated gene involved in MPS to induce or improve phosphate-dissolving capacity in PGPB strains, is an interesting approach.

An attempt to improve MPS in PGPB strains, using this approach, was carried out (Rodríguez et al., 2000b) with a PQQ synthetase gene from Erwinia herbicola. This gene, isolated by Goldstein and Liu (1987), was subcloned in a broadhost range vector (pKT230). The recombinant plasmid was expressed in E. coli, and transferred to PGPB strains of Burkholderia cepacia and Pseudomonas aeruginosa, using tri-parental conjugation. Several of the exconjugants that were recovered in the selection medium showed a larger clearing halo in medium with tricalcium phosphate as the sole $\mathrm{P}$ source. This indicates the heterologous expression of this gene in the recombinant strains, which gave rise to improved MPS ability of these PGPBs. More recently, a genomic integration of the pcc gene of Synechococcus PCC in P. fluorescent 7942 allowed phosphate solubilization in the recipient strain (Kumar Naresh, pers. comm.).

In other work, a bacterial citrate synthase gene was reported to increase exudation of organic acids and $\mathrm{P}$ availability to the plant when expressed in tobacco roots (López-Bucio et al., 2000). Citrate overproducing plants yielded more leaf and fruit biomass when grown under P-limiting conditions, and required less P-fertilizer to achieve optimal growth. This shows the putative role of organic acid synthesis genes in $\mathrm{P}$ uptake in plants.

\section{Concluding remarks}

Although knowledge of the genetics of phosphate solubilization is still scanty, some genes involved in mineral and organic phosphate solubilization have been isolated and characterized. 
Initial achievements in the manipulation of these genes open a promising perspective for obtaining PGPB strains with enhanced phosphate solubilizing capacity, and thus, a more effective use of these microbes as agricultural inoculants.

\section{Acknowledgements}

H.R. received support from Consejo Nacional de Ciencia y Tecnología of Mexico (CONACyT Catedra Patrimonial de Excelencia grant EX-000580). We thank Ira Fogel at CIB for editing the English text.

\section{References}

Armarger N 2002 Genetically modified bacteria in agriculture. Biochimie 84, 1061-1072.

Babu-Khan S, Yeo C, Martin W L, Duron M R, Rogers R and Goldstein A 1995 Cloning of a mineral phosphate-solubilizing gene from Pseudomonas cepacia. Appl. Environ. Microbiol. 61, 972-978.

Bashan Y, Moreno M and Troyo E 2000 Growth promotion of the seawater-irrigated oil seed halophyte Salicornia bigelovii inoculated with mangrove rhizosphere bacteria and halotolerant Azospirillum spp. Biol. Fertil. Soils 32, 265-272.

Baskanova G and Macaskie L E 1997 Microbially-enhanced chemisorption of nickel into biologically-synthesized hydrogen uranyl phosphate: a novel system for the removal and recovery of metals from aqueous solutions. Biotechnol. Bioeng. 54, 319-329.

Beacham I R 1980 Periplasmic enzymes in Gram-negative bacteria. Int. J. Biochem. 10, 877-883.

Bonthrone K M, Baskanova G, Lin F and Macaskie L E 1996 Bioaccumulation of nickel by intercalation into polycrystalline hydrogen uranyl phosphate deposited via an enzymatic mechanism. Nat. Biotechnol. 14, 635-638.

de Lorenzo V, Herrero M, Jakubzik U and Timmis K N 1990 Mini-Tn5 transposon derivatives for insertion mutagenesis, promoter probing and chromosomal insertion of cloned DNA in Gram-negative Eubacteria. J. Bacteriol. 172, 65686572 .

Deng S, Summers M L, Kahn M L and McDermontt T R 1998 Cloning and characterization of a Rhizobium. meliloti nonspecific acid phosphatase. Arch. Microbiol. 170, 18-26.

Deng S, Elkins J G, Da L H, Botero L M and McDermott T R 2001 Cloning and characterization of a second acid phosphatase from Sinorhizobium meliloti strain 104A14. Arch. Microbiol. 176, 255-263.

Fraga R, Rodríguez H and Gonzalez T 2001 Transfer of the gene encoding the Nap A acid phosphatase from Morganella morganii to a Burkholderia cepacia strain. Acta. Biotechnol. 21, 359-369.

Glick B R 1995 The enhancement of plant growth by free living bacteria. Can. J. Microbiol. 41, 109-117.
Goldstein A H and Liu S T 1987 Molecular cloning and regulation of a mineral phosphate solubilizing gene from Erwinia herbicola. Biotechnology 5, 72-74.

Goldstein A H 1996 Involvement of the quinoprotein glucose dehydrogenase in the solubilization of exogenous phosphates by Gram-negative bacteria. In Phosphate in Microorganisms: Cellular and Molecular Biology. Eds. A TorrianiGorini, E Yagil and S Silver. pp. 197-203. ASM Press, Washington, DC.

Golovan S, Wang G, Zhang J and Forsberg C W 2000 Characterization and overproduction of the Escherichia coli appA encoded bifunctional enzyme that exhibits both phytase and acid phosphatase activities. Can. J. Microbiol. 46, 59-71.

Iddris E E, Makarewicz O, Farouk A, Rosner K, Greiner R, Bochow H, Richter T and Borris R 2002 Extracellular phytase activity of Bacillus amyloliquefaciens FZB45 contributes to its plant-growth-promoting effect. Microbiology 148, 2097-2109.

Igual J M, Valverde A, Cervantes E and Velázquez E 2001 Phosphate-solubilizing bacteria as inoculants for agriculture: use of updated molecular techniques in their study. Agronomie $21,561-568$.

Illmer P and Shinnera F 1995 Solubilization of inorganic calcium phosphates. Solubilization mechanisms. Soil Biol. Biochem. 27, 257-263.

Kerovuo J, Lauraeus M, Nurminen P, Kalkinen $\mathrm{N}$ and Apajalahti J 1998 Isolation, characterization, molecular gene cloning, and sequencing of a novel phytase from Bacillus subtilis. Appl. Environ. Microbiol. 64, 2079-2085.

Kim K Y, McDonald G A and Jordan D 1997 Solubilization of hydroxypatite by Enterobacter agglomerans and cloned Escherichia coli in culture medium. Biol. Fert. Soils 24, 347-352.

Kim Y O, Lee J K, Kim H K, Yu J H and Oh T K 1998a Cloning of the thermostable phytase gene (phy) from Bacillus sp. DS11 and its overexpression in Escherichia coli. FEMS Microbiol. Lett. 162, 185-191.

Kim K Y, Jordan D and Krishnan H B 1998b Expression of genes from Rahnella aquatilis that are necessary for mineral phosphate solubilization in Escherichia coli. FEMS Microb. Lett. 159, 121-127.

Krishnaraj P U and Goldstein A H 2001 Cloning of a Serratia marcescens DNA fragment that induces quinoprotein glucose dehydrogenase-mediated gluconic acid production in Escherichia coli in the presence of stationary phase Serratia marcescens. FEMS Microbiol. Lett. 205, 215-220.

Krishnaraj P U, Sadasivam K V and Khanuja S PS 1999 Mineral phosphate soil defective mutants of Pseudomonas sp. express pleiotropic phenotypes. Curr. Sci. (Bangalore, India) 76, 1032-1034.

Lei X G and Stahl C H 2001 Biotechnological development of effective phytases for mineral nutrition and environmental protection. Appl. Microbiol. Biotechnol. 57, 474-481.

Liu S T, Lee L Y, Taj C Y, Hung C H, Chang Y S, Wolfrang J H, Rogers R and Goldstein A H 1992 Cloning of an Erwinia herbicola gene necessary for gluconic acid production and enhanced mineral phosphate solubilization in Escherichia coli HB101: nucleotide sequence and probable involvement in biosynthesis of the coenzyme Pyrroloquinoline Quinone. J. Bacteriol. 174, 5814-5819.

López-Bucio J, de la Vega O M, Guevara-García A and Herrera-Estrella L 2000 Enhanced phophorus uptake in 
transgenic tobacco plants that overproduce citrate. Nat. Biotechnol. 18, 450-453.

Macaskie L E, Yong P, Doyle T C, Roig M G, Díaz M and Manzano T 1997 Bioremediation of uranium-bearing wastewater: biochemical and chemical factors affecting bioprocess application. Biotechnol. Bioeng. 53, 100-109.

Morrissey J P, Walsh O’Donnell U F; A, Moenne-Loccoz Y and O'Gara F 2002 Exploitation of genetically modified inoculants for industrial ecology applications. Antonie van Leeuwenhoek 81, 599-606.

Reilly T J, Baron G S, Nano F and Kuhlenschmidt M S 1996 Characterization and sequencing of a respiratory burstinhibiting acid phosphatase from Francisella tularensis. J. Biol. Chem. 271, 10973-10983.

Richardson A E 1994 Soil microorganisms and phosphorous availability. In Soil Biota: Management in Sustainable Farming Systems. Eds. CE Pankhurst, BM Doube and VVSR Gupta. pp. 50-62. CSIRO, Victoria, Australia.

Richardson A E, Hadobas P A and Hayes J E 2001a Extracellular secretion of Aspergillus phytase from Arabidopsis roots enables plants to obtain phosphorous from phytate. Plant J 25, 641-649.

Richardson A E, Hadobas P A, Hayes J E, O'Hara C P and Simpson R J 2001b Utilization of phosphorus by pasture plants supplied with myo-inositol hexaphosphate is enhanced by the presence of soil micro-organisms. Plant Soil 229, 4756.

Rodríguez E, Han Y and Lei X G 1999 Cloning, sequencing and expression of an Escherichia. coli acid phopshatase/ phytase gene (appA2) isolated from pig colon. Biochem. Biophys. Res. Comm. 257, 117-123.

Rodríguez H and Fraga R 1999 Phosphate solubilizing bacteria and their role in plant growth promotion. Biotechnol. Adv. 17, 319-339.

Rodríguez H, Gonzalez T and Selman G 2000b Expression of a mineral phosphate solubilizing gene from Erwinia herbicola in two rhizobacterial strains. J. Biotechnol. 84, 155-161.

Rodríguez H, Rossolini G M, Gonzalez T, Jiping L and Glick B R 2000a Isolation of a gene from Burkholderia cepacia IS-16 encoding a protein that facilitates phosphatase activity. Curr. Microbiol. 40, 362-366.
Rossolini G M, Shipa S, Riccio M L, Berlutti F, Macaskie L E and Thaller M C 1998 Bacterial non-specific acid phosphatases: physiology, evolution, and use as tools in microbial biotechnology. Cell Mol. Life Sci. 54, 833-850.

Tarafdar J C and Jung A 1987 Phosphatase activity in the rhizosphere and its relation to the depletion of soil organic phosphorus. Biol. Fertil. Soils 3, 199-204.

Tarafdar J C and Claassen N 1988 Organic phosphorus compounds as a phosphorus source for higher plants through the activity of phosphatases produced by plant roots and microorganisms. Biol. Fertil. Soils 5, 308-312.

Thaller M C, Berlutti F, Schippa S, Lombardi G and Rossolini G M 1994 Characterization and sequence of PhoC, the principal phosphate-irrepressible acid phosphatase of Morganella morganii. Microbiology 140, 13411350.

Thaller M C, Berlutti F, Schippa S, Iori P, Passariello C and Rossolini G M 1995a Heterogeneous patterns of acid phosphatases containing low-molecular-mass polypeptides in members of the family Enterobacteriaceae. Int. J. Syst. Bacteriol. 4, 255-261.

Thaller M C, Lombardi G, Berlutti F, Schippa S and Rossolini G M 1995b Cloning and characterization of the NapA acid phosphatase/phosphotransferase of Morganella morganii: identification of a new family of bacterial acid phosphatase encoding genes. Microbiology 140, 147-151.

Tye A J, Siu F K, Leung T Y and Lim B L 2002 Molecular cloning and the biochemical characterization of two novel phytases from Bacillus subtilis 168 and Bacillus licheniformis. Appl. Microbiol. Biotechnol. 59, 190-197.

Wanner B L 1996 Phosphorus assimilation and control of the phosphate regulon. In Escherichia Coli and Salmonella, Cellular and Molecular Biology,. Eds. FC Niedhardt, R Curtiss III, JL Ingraham, EC Lin, KB Low, B Magasanik, WS Reznikoff, M Riley, M Schaechter and HE Umbarger. pp. 1357-1381. 2nd edition, 1ASM Press, Washington, DC.

Yanming H, Wilson D B and Lei X G 1999 Expression of an Aspergillus niger phytase gene (phyA) in Saccharomyces cerevisiae. Appl. Environ. Microbiol. 65, 15-18. 